\title{
Neonatal Bloodstream Infections
}

\author{
Rasha M. EL-Morsi ${ }^{\text {** }}$, Soha M. El-Masry² and Enas Abdulaziz Hamad ${ }^{3}$ \\ ${ }^{1}$ Department of Microbiology and Immunology, Faculty of Pharmacy, Delta University, Egypt \\ ${ }^{2}$ Department of Pharmaceutics, Faculty of Pharmacy, Damanhour University, \\ Damanhour, Egypt \\ ${ }^{3}$ Department of Microbiology and Immunology, Faculty of Medicine, \\ Mansoura University, Egypt \\ *Corresponding author
}

\section{A B S T R A C T}

\section{Keywords}

Neonatal sepsis, Klebsiella species, Late-onset sepsis,

Preterm infants, Blood stream infections

\section{Article Info}

Accepted:

08 January 2020

Available Online:

10 February 2020
Neonates are immune-compromised individuals who are prone to infection. Neonatal sepsis has significant morbidity and mortality. This study is a retrospective study to assess the most important bacteria and the risk factors responsible for bloodstream in infection in Neonatal Intensive Care Unit, Mansoura University Hospital, Egypt. Gram negative bacteria were responsible for most cases of neonatal blood stream infections with Klebsiella pneumoniae accounting for the majority of cases (47.2\%). lateonset sepsis $(61.6 \%)$ was more common than early-onset sepsis. The preterm infants represented $63 \%$ of the overall studied cases. Comparison between demographic data of cases with neonatal sepsis caused by Klebsiella and those caused by other bacteria revealed that there were no statistical significant differences between the two groups.

\section{Introduction}

Neonatal sepsis is a clinical syndrome characterized bacteremia and systemic signs and symptoms during the first month of life or it can be defined as a disseminated disease with a positive blood culture during the first month of life (1). Sepsis is considered the most important cause of neonatal mortality and is responsible for $30-50 \%$ of the total neonatal deaths each year in developing countries (2,3). Early onset (within first 72 hours of life) neonatal sepsis is generally acquired from pathogens of maternal genital tract, whereas late onset sepsis (after 72 hours till 28 days of life) has its environmental origin either in the community or in hospital (4).

The most common pathogens of bacterial sepsis and antibiotic sensitivity patterns vary in different parts of the world (5) and 
sometimes changes from one center to another within the same country (6). Sepsis with Gram-negative microorganisms increasingly reported nowadays $(7 ; 8)$. In general, gram negative bacteria are the predominant causes of neonatal sepsis and among them Klebsiella pneumoniae the most common pathogen, especially in developing countries $(9,10,11)$. The widespread use of antimicrobial agents results in the appearance of multi-resistant strains of Klebsiella in hospitals $(12,13)$.

The aim of this study was to describe different bacterial isolates obtained from blood cultures of neonates and the predisposing risk factor for neonatal infection in the neonatal Intensive Care Unit (NICU) in Mansoura University Hospital, Egypt.

\section{Materials and Methods}

This was a retrospective review of all bacterial isolates in blood cultures obtained from the NICU of Mansoura University Hospital during period extending from August 2012 to August 2015. This neonatal unit cares for both inborn and out born neonates. A list of positive blood cultures was obtained from the Microbiology Diagnostic and Infection Control Unit (MDICU), in the department of Medical Microbiology and Immunology, Faculty of Medicine, Mansoura University Computer Data Warehouse. Information obtained (were available for only 73 out of 91 cases) included identification of the isolated organisms and complete patient medical records (including name, gender, birth date, birth weight, age in days, Gestational age, birth location, results of physical examination, laboratory results, maternal data as mode of delivery and prenatal steroids). A neonate was defined as being $\leq 28$ days of age. Only blood stream infections (BSIs) were included in this study as neonates with clinical signs of sepsis but having negative blood cultures were excluded. Early onset sepsis (EOS) refers to infections during the first $72 \mathrm{hr}$. whereas late onset sepsis (LOS) refers to postnatal acquisition of infections after the first 3 days of life.

Collection of blood samples performed before the start of empirical antibiotic therapy. After proper disinfection of the skin at site of venipuncture, from 0.5 to $1.5 \mathrm{ml}$ of blood was withdrawn from infants and sent for blood culture together with a full blood count and $\mathrm{C}$ reactive protein (CRP). The CRP was repeated after 24 hours. The blood then, inoculated immediately into blood culture bottles containing either $50 \mathrm{ml}$ tryptic soy broth or brain heart infusion broth. Samples were transported to laboratory and incubated at $37^{\circ} \mathrm{C}$ (14) the blood culture medium vials sent to Microbiology Diagnostic and Infection Control Unit (MDICU), in the department of Medical Microbiology and Immunology, Faculty of Medicine, Mansoura University. (MDICU) laboratory for cultivation and subsequent processing.

The blood cultures were incubated aerobically at $37^{\circ} \mathrm{C}$ and observed daily for the first 3 days for the presence of visible microbial growth by one of the following: hemolysis, air bubbles (gas production), and coagulation of broth. At the same time, subcultures were made during three successive days on enriched and selective media including blood, chocolate, MacConkey, and mannitol salt agar plates and examined for growth after 24-48 hours of incubation. The same protocol was repeated until the 7th day before blood culture was considered to be free of microorganisms (15).

\section{Data analysis}

Data was collected, classified, tabulated and analyzed. Tests of significance were applied at appropriate places and interpretation was 
done accordingly. To evaluate the difference between the categories, Student's t-test was used as a test of significance. A p-value of less than 0.05 was considered statistically significant (16).

\section{Results and Discussion}

Gram negative bacteria were responsible for most cases of neonatal blood stream infections in Mansoura University Hospital during the period of this study and Klebsiella pneumoniae (47.2\%) was the most frequent isolated pathogen as shown in Table (1)

Over the period of the study, 91 cases of neonates admitted in NICU of Mansoura University Hospitals and had a culture proven sepsis. Complete patient medical records (including name, gender, birth date, birth weight, age in days, Gestational age, birth location, results of physical examination, laboratory results, maternal data as mode of delivery and prenatal steroids) were available for only 73 out of $91(80 \%)$ cases.

\section{Organism isolated in early-onset (EOS) and late-onset (LOS) septicemia}

Early onset sepsis (EOS) refers to infections during the first $72 \mathrm{hr}$. whereas late onset sepsis (LOS) refers to postnatal acquisition of infections after the first 3 days of life (Bizzarro et al., 2008). As shown in Table 2, late-onset sepsis was more common than early-onset sepsis as, early onset sepsis detected in $28(38.4 \%)$ cases and late onset sepsis in $45(61.6 \%)$ cases.

\section{Maternal and neonatal data of neonates investigated for sepsis}

Both Maternal and neonatal data of neonates investigated for sepsis shown in Table 3 and Table 4. Of the 73 studied neonates, $63 \%$ were males and the rest $37 \%$ were females.
The preterm infants represented $63 \%$ of the overall studied cases. Most of the studied cases $(98.7 \%)$ were born in the health care facilities (hospitals/ private clinics), while only one case was born in home. Caesarean section represented the major delivery mode $(80.8 \%)$. The majority of the studied neonates $(63 \%)$ had either low birth weight (LBW) or very low birth weight (VLBW).

Table 5 summarized the clinical presentations and signs among the studied cases with sepsis. As shown from this table, prematurity and respiratory distress syndrome were the most common clinical diagnosis among the studied cases.

Comparison between demographic and clinical data of neonates infected by Klebsiella and those infected with other bacteria

Demographic data of cases with neonatal sepsis caused by Klebsiella were compared with those caused by other bacteria. Table 6 shows no statistical significant differences in the mean of age, gestational age, and birth weight of Klebsiella Infected neonates and other neonates.

Neonatal sepsis represents a very important health problem all over the world (17). Pathogens encountered in neonatal sepsis vary worldwide (even vary from hospital to hospital in the same country).These differences in bacterial etiology of neonatal sepsis attributed to many factors such as environmental differences, patterns of antibiotics used, nursery practices, differences in the supportive care and infection control practices (18).

In this study, Gram-negative bacteria represent the major cause of bloodstream infections in neonates in Mansoura University Hospital and responsible for about $66 \%$ of the 
overall cases. Neonatal sepsis caused by Gram-negative bacteria is more frequent in developing countries (19). A comparable results to our study were recorded by Kamath et al., (2010) who reported that $71.8 \%$ of BSIs in India were caused by Gram-negative bacteria, with Klebsiella species accounting for $16.4 \%$, Pseudomonas spp. $13.6 \%$, E. coli $11.8 \%$, Enterobacter spp. $11.4 \%$ and Acinetobacter spp. $10 \%$ (19).

Table.1 Microbiological profile found in positive blood cultures from neonates

\begin{tabular}{|l|c|c|}
\hline \multicolumn{1}{|c|}{ Isolated microorganism } & No of isolates & $\%$ \\
\hline Gram - negative bacteria & \multicolumn{2}{c|}{} \\
\hline Klebsiella pneumonia & 43 & $\mathbf{4 7 . 2} \%$ \\
\hline Escherichia coli & 10 & $\mathbf{1 1 \%}$ \\
\hline Acinetobacter species & 1 & $\mathbf{1 . 1 \%}$ \\
\hline Pseudomonas species & 5 & $\mathbf{5 . 5 \%}$ \\
\hline Proteus mirabilis & 1 & $\mathbf{1 . 1 \%}$ \\
\hline Gram - positive bacteria & 3 & \\
\hline a hemolytic streptococci & $\mathbf{1 8}$ & $\mathbf{1 9 . 8 \%}$ \\
\hline Staphylococcus aureus & 1 & $\mathbf{1 . 1 \%}$ \\
\hline MRSA* & & \\
\hline Fungi & 9 & $\mathbf{9 . 9 \%}$ \\
\hline Candida species & 91 & $\mathbf{1 0 0 \%}$ \\
\hline Total & & \\
\hline
\end{tabular}

Table.2 Organism isolated in early-onset (EOS) and late-onset (LOS) septicemia

\begin{tabular}{|c|c|c|c|}
\hline Isolated microorganism & $\begin{array}{c}\text { Early-onset } \\
\leq 72 \mathrm{hr}\end{array}$ & $\begin{array}{c}\text { Late- onset } \\
>72 \mathrm{hr} .\end{array}$ & $\begin{array}{l}\text { Total no. of } \\
\text { organism }\end{array}$ \\
\hline \multicolumn{4}{|l|}{ Gram - negative bacteria } \\
\hline Klebsiella pneumonia & 11 & 20 & 31 \\
\hline Escherichia coli & 3 & 6 & 9 \\
\hline Acinetobacter species & - & 1 & 1 \\
\hline Pseudomonas species & 2 & 2 & 4 \\
\hline Proteus mirabilis & 1 & - & 1 \\
\hline \multicolumn{4}{|l|}{ Gram - positive bacteria } \\
\hline a hemolytic streptococci & 3 & - & 3 \\
\hline Staphylococcus aureus & 7 & 9 & 16 \\
\hline MRSA & - & 1 & 1 \\
\hline \multicolumn{4}{|l|}{ Fungi } \\
\hline Candida species & 1 & 6 & 7 \\
\hline Total & $28(38.4 \%)$ & $45(61.6 \%)$ & 73 \\
\hline
\end{tabular}


Table.3 Neonatal data of the neonates investigated for sepsis

\begin{tabular}{|l|l|}
\hline Features & Total $(\mathbf{n}=\mathbf{7 3})$ number \% \\
\hline $\begin{array}{l}\text { Sex: } \\
\text { Male }\end{array}$ & $\begin{array}{l}\mathbf{4 6}(\mathbf{6 3} \%) \\
\text { Female }\end{array}$ \\
\hline $\begin{array}{l}\text { Birth weight: } \\
\leq 1500 \text { g (VLBL) }\end{array}$ \\
$\begin{array}{l}\mathbf{1 5 0 1}-2500(\mathrm{LBW}) \\
>2500\end{array}$ & $\begin{array}{l}\mathbf{3 0}(\mathbf{4 1 \%}) \\
\mathbf{1 6}(\mathbf{2 1 . 9 \%})\end{array}$ \\
\hline
\end{tabular}

Table.4 Maternal data of neonates investigated for sepsis

\begin{tabular}{|l|c|}
\hline \multicolumn{1}{|c|}{ Characteristics } & Total $(\mathbf{n}=\mathbf{7 3})$ number \% \\
\hline Gestational age & \\
$\leq 33$ weeks (preterm) & $31(42.5 \%)$ \\
34-36 (late preterm) & $15(20.5 \%)$ \\
$\geq 37$ weeks (term) & $27(37 \%)$ \\
\hline Birth location & $58(79.5 \%)$ \\
Hospital & $14(19.17 \%)$ \\
Private clinic & $1(1.36 \%)$ \\
Home & $14(19.17 \%)$ \\
\hline Delivery Mode & $59(80.82 \%)$ \\
\hline Vaginal/Spontaneous & $21(28.76 \%)$ \\
\hline Caesarean section & \\
\hline Prenatal steroids & \\
\hline
\end{tabular}

Table.5 Clinical presentations and signs accompanied the diagnosis among studied cases with suspected sepsis

\begin{tabular}{|l|c|}
\hline Clinical signs/ accompanied diagnosis & Number (\%) \\
\hline Respiratory distress syndrome & $18(24.6 \%)$ \\
\hline Apnea & $2(2.7 \%)$ \\
\hline Hypothermia & $2(2.7 \%)$ \\
\hline Jaundice & $4(5.5 \%)$ \\
\hline Prematurity & $46(63 \%)$ \\
\hline Convulsions and neurologic alterations & $8(10.9 \%)$ \\
\hline Poor feeding & $6(8.2 \%)$ \\
\hline Hypoxic ischemia & $2(2.7 \%)$ \\
\hline Neonatal hypoglycemia & $2(2.7 \%)$ \\
\hline Neonatal pneumonia & $2(2.7 \%)$ \\
\hline Bleeding tendency or hemorrhage & $1(1.4 \%)$ \\
\hline
\end{tabular}


Table.6 Comparison between demographic data of neonates infected by Klebsiella and those infected with other bacteria

\begin{tabular}{|l|c|c|c|}
\hline \multicolumn{1}{|c|}{ Variables } & $\begin{array}{c}\text { Klebsiella } \\
\mathbf{N = 3 1}\end{array}$ & $\begin{array}{c}\text { Other bacteria } \\
\mathbf{N = 4 2}\end{array}$ & p. value \\
\hline $\begin{array}{l}\text { Gestational age } \\
\text { (weeks)(mean } \pm \text { SE) }\end{array}$ & $34.5 \pm 0.8$ & $34.2 \pm 0.7$ & 0.774 \\
\hline Age $($ day)(mean \pm SE) & $8.3 \pm 1.3$ & $9.4 \pm 1.3$ & 0.541 \\
\hline Weight(g) (mean \pm SE) & $2071.1 \pm 143.4$ & $2156.6 \pm 169.8$ & 0.702 \\
\hline
\end{tabular}

Table.7 Results of white blood count (WBC), PLT and C - reactive protein (CRP) of studied neonates

\begin{tabular}{|l|l|l|l|}
\multicolumn{1}{|c|}{$\begin{array}{c}\text { Clinical } \\
\text { manifestations }\end{array}$} & \multicolumn{1}{|c|}{$\begin{array}{c}\text { Klebsiella } \\
\mathbf{N = 3 1}\end{array}$} & $\begin{array}{c}\text { Other bacteria } \\
\mathbf{N = 4 2}\end{array}$ & \multicolumn{1}{|c|}{ p. value } \\
\hline $\begin{array}{l}\text { WBC } \\
\text { Range } \\
\text { Mean +SE }\end{array}$ & $\begin{array}{l}5.3-87.9 \\
21.4 \pm 3.5\end{array}$ & $\begin{array}{l}6.7-69.4 \\
18.9 \pm 2.4\end{array}$ & 0.575 \\
\hline $\begin{array}{l}\text { PLT } \\
\text { Range } \\
\text { Mean +SE }\end{array}$ & $\begin{array}{l}22-678 \\
173.9 \pm 30.5\end{array}$ & $\begin{array}{l}28-679 \\
169.9 \pm 30.9\end{array}$ & 0.927 \\
\hline $\begin{array}{l}\text { CRP } \\
\text { Range } \\
\text { Mean +SE }\end{array}$ & $12-180$ & $11-260$ & \\
\hline
\end{tabular}

Our results demonstrated that, Klebsiella pneumonia is the main causative agents for neonatal bloodstream infections and accounts for $47.2 \%$ of all cases. Other studies from Egypt reported that Klebsiella pneumoniae is the main organism associated with neonatal sepsis $(20 \& 21)$.

Our results are somewhat higher to what reported by Mohammed and El Seifi, 2014 in Zagazig University Hospital in Egypt, who found that Klebsiella was the most frequently isolated bacteria in neonatal intensive care unit and represent $34.2 \%$ of the recovered microorganisms (22).

By contrast, In Europe, Gram-positive bacteria, caused most of nosocomial neonatal infections (76.4\%) with CoNS being the most frequently occurring pathogens (23).

In this study, E.coli represented the second cause of neonatal Gram-negative blood stream infections and accounts for $11 \%$ of all the cases, followed by Pseudomonas species (5.5\%). Ghotaslou et al., 2007, reported similar results that $K$. pneumoniae was the most common Gram-negative causing neonatal sepsis and E.coli is the second most common among Gram-negative isolates (24). On the other hand, other Gram-negative bacteria such as $P$. aeruginosa and Enterobacter spp were identified as the most common Gram-negative isolates associated with neonatal sepsis in other studies (25\&26). 
Staphylococcus aureus remain a very important neonatal pathogen. In this study, Staphylococcus aureus represented $19.8 \%$ of the overall blood stream infections among the studied cases. This was in accordance with what was mentioned by Zaidi et al., (2005) who reported that, Staphylococcus aureus in developing countries, responsible for $8-22 \%$ of neonatal blood-stream infections (27)

Candida spp. was isolated from $9.9 \%$ of the studied cases. Lower incidence was reported in Kenya by Kohli-Kochhar et al., 2011 and in India by Gandhi et al., 2013 as they reported incidence of $(2.41 \%)$ and $(2.63 \%)$ respectively $(28,29)$.

Early onset sepsis usually presents within the first 72 hours of life and is associated with acquisition of microorganisms from the mother either an ascending infection from the cervix (may be caused by organisms that colonize in the mother's genitourinary tract) or Trans placental infection. While, late onset sepsis usually presents after 72 hours of life and is acquired from the care-giving environment. (30).

In the current study, early-onset sepsis (EOS) was less common than late-onset sepsis (LOS) (38.4\% versus 61.6\%). This finding was in accordance with previous study performed by Shehab El-Din et al., 2015 (between March 2011 and August 2012) who reported an incidence of $55.8 \%$ for LOS and $44.2 \%$ for EOS (15). In addition, other studies by Kayange et al., 2010 and Ballot et al., 2012 reported a higher incidence for LOS than EOS $(31,32)$.

The male neonate is predominant in almost all studies of neonatal sepsis. In this study, the percentage of male neonates is $63.0 \%$. The explanation of this phenomenon is not clear but this may be due to a sex-linked factor related to host susceptibility (33 \& 15$)$.
Moreover, the ESBL phenotype of $K$. pneumonia has been reported more frequently in males (34).

Neonates, especially preterm and with very low birth weight (VLBW) are more susceptible to acquire nosocomial infections because of immaturity of their immune system, receiving total parenteral nutrition in the NICU, prolonged hospital stay and exposure to invasive procedures (35).

Generally, birth weight is inversely proportional to incidence of neonatal sepsis. Many studies confirm this correlation, Kaufman and Fairchild, 2004 reported that a serious systemic infections occurred in $20 \%$ of very-low-birth-weight $(<1500 \mathrm{~g})$ preterm infants (36). In this work, very low birth weight neonates (VLBW) and low birth weight neonates (LBW) represent $41 \%$ and $22 \%$ respectively of the overall cases. The same results were reported by Mutlu et al., 2011 who recorded forty-one percent for VLBW neonates with sepsis (37). Premature neonates are more susceptible to nosocomial infections (38). Most of the neonates in this study were premature. Both preterm neonates ( $\leq 33$ weeks) and late preterm (34-36 weeks) represented together $63 \%$ of the studied cases. A comparable result was reported by Mutlu et al., 2011 who reported that $66 \%$ of the neonates having sepsis were premature (37).

Generally, prematurity and low birth weight considered as the two most important factors exposing the neonates to infections and the premature infants with low birth weight have a 3 to 10 fold higher incidence of infection and sepsis than do full-term normal birth weight infants (31).

In this study, most of neonates having sepsis was born via Caesarean section (80.8\%).This is similar to what was reported by previous studies (26 \& 39). While Wrener et al., 2012 
reported that there was no significant difference in intra-ventricular hemorrhage, subdural hemorrhage, seizure, or sepsis between the cesarean delivery and vaginal delivery groups (40). The Cesarean delivery when compared with vaginal delivery, it was associated with increased odds of respiratory distress syndrome.

In this study, prenatal steroids were given in $28.7 \%$ of the studied cases. Some studies found that, the incidence of neonatal infections were not affected significantly with prenatal steroids (41). In contrast, several studies suggested that steroid treatment was considered as an independent risk factor for early onset neonatal sepsis (EOS) (42\& 43). Indeed, the multiple courses of steroids may have a significant effect over the appearance of neonatal sepsis. Single course of steroids is recommended than multiple courses and have the same effect (42).

In this work, demographic data of cases with neonatal sepsis caused by Klebsiella were compared with those caused by other bacteria and there is no statistical significant differences in the mean of age, gestational age, birth weight, WBC, PLT and CRP of Klebsiella Infected neonates and neonates infected by other bacteria.

\section{References}

1. Edwards MS. Postnatal infections. In: Fanaoff and Martins Neonatalperinatal Medicine, 8 th ed. Philadelphia: Mosby Elsevier 2006; 791-804.

2. Bang RA, Bactule SB, Reddy HM, Deshmukh MD. Effect of home based neonatal care and management of sepsis on neonatal mortality: field trial in rural India. Lancet1 1999; 354: 1955-61.

3. Stoll BJ. The global impact of neonatal infection. Clin Perinatol 1997; 24: 1-21.

4. Zaidi A., Thaver D., Ali S. and Khan T. (2009). Pathogens associated with sepsis innewborns and young infants in developing countries. Pediatr Infect Dis J.; 28:S10-S18.

5. Luck S., Torny M., d'Agapeyeff K., Pitt A., Heath P., Breathnach A. and Russel A. (2003). Estimated early onset group B streptococcal neonattal disease. Lancet.; 361(9373):1953-54.

6. Desinor O., Silva J. and Menos M. (2004). Neonatal sepsis and meningitis in Haili. J. Trop. Pediatr.; 50(1): 4850.

7. Bark A. (2003). Intravenous linesrelated sepsis in newborn babies admitted to NICU in a developing country. J. Trop. Pediatr.; 49(5):259267.

8. Joshi S., Ghole V. and Niphadkar K. (2000). Neonatal Gram-negative bacteremia. Indian $J$ Pediatr.; 67(1):27-32.

9. 10 Kaistha N, Mehta M, Singla N, Garg R, Chander J. Neonatal septicemia isolates and resistance patterns in a tertiary care hospital of North India. J Infect Dev Ctries 2009; 4: 55-7.

10. Waliullah MS, Islam MN, Siddika M, Hossain MK, Hossain MA. Risk factors, clinical manifestation and bacteriological profile of neonatal sepsis in a tertiary level pediatric hospital. Mymensingh Med J 2009; 18 : S66-S72.

11. Shitaye D, Asrat D, Woldeamanuel Y, Worku B. Risk Factors and etiology of neonatal sepsis in Tikur Anbessa University Hospital, Ethiopia. Ethiop Med J 2010; 48: 11-21.

12. Selden R, Lee S, Wang WLL, Bennett JV, Eickhoff TC. Nosocomial Klebsiella infections: intestinal 
colonization as a reservoir. Ann. Intern. Med 1971; 74:657-64.

13. Wu K, Wang F, Sun J, et al., Class 1 integron gene cassettes in multidrugresistant Gram-negative bacteria in southern China. Int $J$ Antimicrob Agents 2012; 40: 264-67.

14. Koneman E., Allen S., Janda W., Schrecjenberger P. and Winn W. (1997a). "Introduction to microbiology. PartII: Guidelines for collection, transport, processing analysis and reporting of cultures from specific specimen sources". Cited by Koneman, E.W., Allen, S.D., Janda, W.M., Schrecjenberger, P.C. and Winn, W.C. (eds.), In:Color Atlas and Textbook of Diagnostic Microbiology, $5^{\text {th }}$ ed., PP:121-170. Lippincott-Raven, Philadelphia.

15. Shehab El-Din E., El-Sokkary M., Bassiouny M. and Hassan R. (2015). Epidemiology of Neonatal Sepsis and Implicated Pathogens: A Study from Egypt. BioMed Research International.; 2015, 509484, 11 pages.

16. Yang-chun F., Yan-chun H. and Xiumin M. (2017).The application of Student's t-test in internal quality control of clinical laboratory. Frontiers in Laboratory Medicine.; 1(3):125-28.

17. Mohsen L., Ramy N., Saied D., Akmal D., Salama N., Abdel Haleimand M. and Aly H. (2017). Emerging antimicrobial resistance in early and late-onset neonatal sepsis. Antimicrob Resist Infect Control.; 6:63.

18. Ghotaslou R., Ghorashi Z., Naheai M. (2007). Klebsiella pneumoniae in neonatal sepsis: A 3-year study in the pediatric hospital of Tabriz, Iran. Jpn. J.Infect.Dis.; 60:126-8.

19. Kamath S., Mallaya S., Shenoy S.
(2010): Nosocomial infections in neonatal intensive care units: profile, risk factor assessment and antibiogram. Indian J Pediatr.; 77:379.

20. Idris A., Angie T., Reem M., et al., (2014). Neonatal sepsis and antibiotic susceptibility in NICUs of Cairo University Hospitals. J of Arab Child.; 25 (4): 87 - 97.

21. Mashaly G., El-Sabbagh A., ElKazzaz S., et al., (2016). MBL2 gene polymorphism and the association with neonatal sepsis in Egyptian neonates, a case control study. Open $J$ Immunol.; 6: 111-9.

22. Mohammed D. and El Seifi O. (2014). Bacterial nosocomial infections in neonatal intensive care unit, Zagazig University Hospital, Egypt. Egypt Paediatr Assoc Gaz.; 62(3-4): 72-9.

23. Urrea M., Iriondo M., Thio M., et al., (2003). A prospective incidence study of nosocomial infections in a neonatal care unit. AJIC.; 31(8): 505-7.

24. Ghotaslou R., Ghorashi Z., Naheai M. (2007). Klebsiella pneumoniae in neonatal sepesis: A 3-year study in the pediatric hospital of Tabriz, Iran. Jpn. J.Infect.Dis.; 60:126-8.

25. Cecilia C., Mary Ann C., Elizabeth E., Jonathan G., Joanne J. and Cecille Y. (2011). Etiology of neonatal sepsis in five urban hospitals in the Philippines. PIDSP Journal.; 12: 75-85.

26. Afsharpaiman S., Torkaman M., Saburi A., Farzaampur A., Amirsalari S. and Kavehmanesh Z. (2012).Trends in incidence of neonatal sepsis and antibiotic susceptibility of causative agents in two neonatal intensive care units in Tehran, I.R Iran. J Clin Neonatol.; 1(3): 124-30.

27. Zaidi A., Huskins W., Thaver D., Bhutta Z, Abbas Z. and Goldmann D. (2005). Hospital-acquired neonatal 
infections in developing countries. Lancet. ; 365 (9465): 1175- 88.

28. Kohli-Kochhar R., Omuse G. and Revathi G. (2011). A ten-year review of neonatal bloodstream infections in a tertiary private hospital in Kenya. $J$ Infect Dev Ctries.; 5(11): 799-803.

29. Gandhi S., Ranjan N., Ranjan N. and Masani M. (2013). Incidence of neonatal sepsis in tertiary care hospital: an overview. Int $J$ Med Sci Public Health.; 2(3): 548-52.

30. El Badawy A., ElSebaie D., Khairat S. and Fouad S. (2005). Astudy of microbiological pattern of neonatal sepsis. Alex J Pediatr.; 19: 357-67.

31. Kayange N., Kamugisha E., Mwizamholya D., Jeremiah S. and Mshana S. (2010). Predictors of positive blood culture and deaths among neonates with suspected neonatal sepsis in a tertiary hospital, Mwanza-Tanzania. BMC Pediatrics.; 10: 39.

32. Ballot D., Nana T., Sriruttan C. and Cooper P. (2012). Bacterial blood stream infections in neonates in a developing country. ISRN Pediatrics.; 2012: 508512.

33. Baley J. and Goldfarb J. (2001). Neonatal infections. In: Marshall, H., Avory, A. F., and Eliza, H. B. (eds.): Care of High Risk Neonate. $15^{\text {th }}$ ed. St Louis: W.B, Saunders Company; P: 363-392.

34. Khan E., Ejaz M., Zafar A., Jabeen K., Shakoor S., Inayat R. and Hasan R. (2010). Increased isolation of ESBL producing Klebsiella pneumoniae with emergence of carbapenem resistant isolates in Pakistan: report from a tertiary care hospital. J Pak Med Assoc.; 60:18690.

35. Clark R., Powers R., White R., et al., (2004). Nosocomial infection in the
NICU: a medical complication or unavoidable problem? J Perinatol.; 24: 382-8.

36. Kaufman D. and Fairchild K. (2004). Clinical microbiology of bacterial and fungal sepsis in very-low-birth-weight infants. Clin Microbiol Rev.; 17(3):638-80.

37. Mutlu M., Aslan Y., Saygin B., Yilmaz G., Lu G. and Köksal I. (2011). Neonatal Sepsis Caused by Gram-negative Bacteria in a Neonatal Intensive Care Unit: A Six Years Analysis. HK J Paediatr (new series) 16:253-7.

38. Saleem A., Shah M., Shaikh A., Mir F. and Zaidi A. (2011). Acinetobacter species meningitis in children: a case series from Karachi. Pakistan. $J$ Infect Dev Ctries.; 5: 809-14.

39. Gandhi S., Ranjan N., Ranjan N. and Masani M. (2013). Incidence of neonatal sepsis in tertiary care hospital: an overview. Int $J$ Med Sci Public Health.; 2(3): 548-52.

40. Werner E.,Savitz D., Janevic T., Ehsanipoor R., Thung S., Funai E and Lipkind H. (2012). Mode of Delivery and Neonatal Outcomes in Preterm, Small-for-Gestational-Age Newborns. Obstet Gynecol.; 120(3): 560-4.

41. Wang Y., Tseng H., Yang S., et al., (2012). Effects of antenatal corticosteroids on neonatal outcomes in very-low-birth-weight preterm newborns: a 10-year retrospective study in a medical center. Pediatr Neonatol.; 53(3): 178-83.

42. Mariotti V., Marconi A. and Pardi G. (2004). Undesired effects of steroids during pregnancy. $J$ Matern Fetal Neonatal Med.; 16(2):5-7.

43. Salem S., Sheiner E., Zmora E., et al., (2006). Risk factors for early neonatal sepsis. Arch Gynecol Obstet.; 274: 198-202. 


\section{How to cite this article:}

Rasha M. EL-Morsi, Soha M. El-Masry and Enas Abdulaziz Hamad. 2020. Neonatal Bloodstream Infections. Int.J.Curr.Microbiol.App.Sci. 9(02): 1700-1710.

doi: https://doi.org/10.20546/ijcmas.2020.902.196 